\title{
Induction of a Parafacial Rhythm Generator by Rhombomere 3 in the Chick Embryo
}

\author{
Ana P. Coutinho, ${ }^{1 \star}$ Caroline Borday, ${ }^{2 \star}$ Jonathan Gilthorpe, ${ }^{1}$ Stefan Jungbluth, ${ }^{2}$ Jean Champagnat, ${ }^{2}$ Andrew Lumsden, ${ }^{1}$ \\ and Gilles Fortin ${ }^{2}$ \\ ${ }^{1}$ Medical Research Council Centre for Developmental Neurobiology, King's College London, Guy's Campus, London SE1 1UL, United Kingdom, and \\ ${ }^{2}$ Neurobiologie Génétique et Intégrative, Institut Alfred Fessard, Centre National de la Recherche Scientifique, 91198 Gif-sur-Yvette, France
}

\begin{abstract}
Observations of knock-out mice suggest that breathing at birth requires correct development of a specific hindbrain territory corresponding to rhombomeres (r) 3 and 4. Focusing on this territory, we examined the development of a neuronal rhythm generator in the chick embryo. We show that rhythmic activity in $\mathrm{r} 4$ is inducible after developmental stage 10 through interaction with $\mathrm{r} 3$. Although the nature of this interaction remains obscure, we find that the expression of Krox20, a segmentation gene responsible for specifying $\mathrm{r} 3$ and $\mathrm{r} 5$, is sufficient to endow other rhombomeres with the capacity to induce rhythmic activity in r4. Induction is robust, because it can be reproduced with $\mathrm{r} 2$ and $\mathrm{r} 6$ instead of $\mathrm{r} 4$ and with any hindbrain territory that normally expresses Krox $20(\mathrm{r} 3$, r5) or can be forced to do so $(\mathrm{r} 1, \mathrm{r} 4)$. Interestingly, the interaction between $\mathrm{r} 4$ and $\mathrm{r} 3 / \mathrm{r} 5$ that results in rhythm production can only take place through the anterior border of $\mathrm{r} 4$, revealing a heretofore unsuspected polarity in individual rhombomeres. The $\mathrm{r} 4 \mathrm{rhythm}$ generator appears to be homologous to a murine respiratory parafacial neuronal system developing in $\mathrm{r} 4$ under the control of Krox20 and Hoxa1. These results identify a late role for Krox20 at the onset of neurogenesis.
\end{abstract}

Key words: central pattern generator; transcription factor; Krox20; rhombencephalon; chick embryo; neurogenesis

\section{Introduction}

By developmental HH stage 10 (Hamburger and Hamilton, 1951) in chicks, the hindbrain region is subdivided along the anteroposterior (AP) axis into seven to eight rhombomeres ( $r$ ) and starts neurogenesis (Lumsden and Keynes, 1989). Rhombomere-restricted gene expression patterns such as Krox20 and Hox (for review, see Lumsden and Krumlauf, 1996) orchestrate rhombomere formation. How rhythmic neuronal circuits are generated in relation to rhombomeres is not known. The r3r4 territory has been implicated in rhythmogenesis both by microsurgical rhombomere isolation experiments in chick embryos (Fortin et al., 1999) and by inactivating genes that are involved in specifying r3 or r4 development (e.g., Krox20, Hoxa1) (Jacquin et al., 1996; Helmbacher et al., 1998; Dominguez del Toro et al., 2001; Chatonnet et al., 2002; Borday et al., 2003). Furthermore, physiological studies of neonatal mice have identified rhythmic neurons of the parafacial respiratory group, located ventral to the

\footnotetext{
Received June 18, 2004; revised Sept. 7, 2004; accepted Sept. 7, 2004.

This work was supported by the Centre National de la Recherche Scientifique; the Medical Research Council; the Wellcome Trust; Human Frontier Science Program Grant RG0101/1997-8 to J.C. and A.L.; European Grants "Brainstem Genetics" QLG2-CT-2001-01467, ACI BDP57, and BDP0223; and Direction Générale de I'Armement Contract DSP/STTC00/34/077. C.B. was supported by a fellowship from the Ministry of National Education and Research (France).

${ }^{*}$ A.P.C. and C.B. contributed equally to this work.

Correspondence should be addressed to G. Fortin, Centre National de la Recherche Scientifique, Unité Propre de Recherche 2216, Laboratoire de Neurobiology Génétique et Intégrative, Institut Fédératif de Recherche Alfred Fessard, 1 Avenue de la Terrasse, 91198 Gif-sur-Yvette Cedex, France. E-mail: gilles.fortin@iaf.cnrs-gif.fr.

A.P. Coutinho's present address: Instituto Gulbenkian de Ciencia, Rua da quinta Grande 6, 2780-156 0eiras, Portugal.

DOI:10.1523/JNEUROSCI.2408-04.2004

Copyright $\odot 2004$ Society for Neuroscience $\quad$ 0270-6474/04/249383-08\$15.00/0
}

facial motor nucleus (deriving from $\mathrm{r} 4$ ), as an important component of primary respiratory rhythmogenesis (Mellen et al., 2003; Onimaru and Homma, 2003).

In both mouse and chick embryos, the intrinsic neuronal activity of the hindbrain starts with a low frequency (LF) (range, $\min ^{-1}$ ) bursting pattern. In chick, activity evolves during embryonic day 6 (E6) when each LF burst is followed by a progressive accumulation of cyclical bursts at high frequency (HF) (range, $\mathrm{sec}^{-1}$ ). By E7-E9, network activities are dominated by these episodic activities generated at the facial level (Fortin et al., 1999). In rhombomere isolation experiments in chick, we found that the episodic rhythm in $\mathrm{r} 4$ emerges when $\mathrm{r} 4$ is left in contact with its anterior neighbor (r3) but does not emerge when $\mathrm{r} 4$ is left in contact with only its posterior neighbor, r5 (Fortin et al., 1999).

The aim of the present study was to investigate the relationship between $\mathrm{r} 3$ and $\mathrm{r} 4$, whereby a segmental program initiated in r3 instructs formation of a parafacial rhythmic network. Our approach has centered on grafting individual rhombomeres heterotopically, so as to produce artificial rhombomere pairs. Krox20 is a candidate to initiate the $\mathrm{r} 3$ program as it confers odd identity to rhombomeres 3 and 5 (Giudicelli et al., 2001). We used in ovo electroporation to force Krox20 expression in Krox20negative rhombomeres and to investigate the previously observed polarity of interaction between $\mathrm{r} 3$ and $\mathrm{r} 4$ (Fortin et al., 1999) performed AP reversals of these rhombomere. Altogether, grafting, electroporation, and reversal procedures identify Krox20-expressing territories as sufficient for instructing episodic behavior in $\mathrm{r} 4$, regardless of the cellular environment $(\mathrm{r} 3$, $\mathrm{r} 5, \mathrm{r} 1, \mathrm{r} 4)$ in which the gene is expressed. We also show that the interaction depends on an intrinsic AP polarity in $\mathrm{r} 4$. 


\section{Materials and Methods}

Animals and hindbrain preparations: the rhombomere isolation procedure. Fertilized commercial hens' eggs were incubated to HH9-HH10. Donor neural tubes for the rhombomeregrafting experiments were obtained after the hindbrain had been dissected out and treated with dispase ( $1 \mathrm{mg} / \mathrm{ml}$ in Leibovitz 15 medium) for $15 \mathrm{~min}$. The neural tube, dissected free of adherent tissue using flame-sharpened tungsten needles, was transected at the level of rhombomere boundaries, making sure that the boundary and the immediately adjacent cells were excised; the AP orientation of the excised rhombomere was marked by leaving tags of dorsal ectoderm on one-half of the explant. All rhombomere explants included both left and right sides. For transplantation, stage-matched host eggs were windowed and the vitelline membrane reflected. A gap in the neural tube
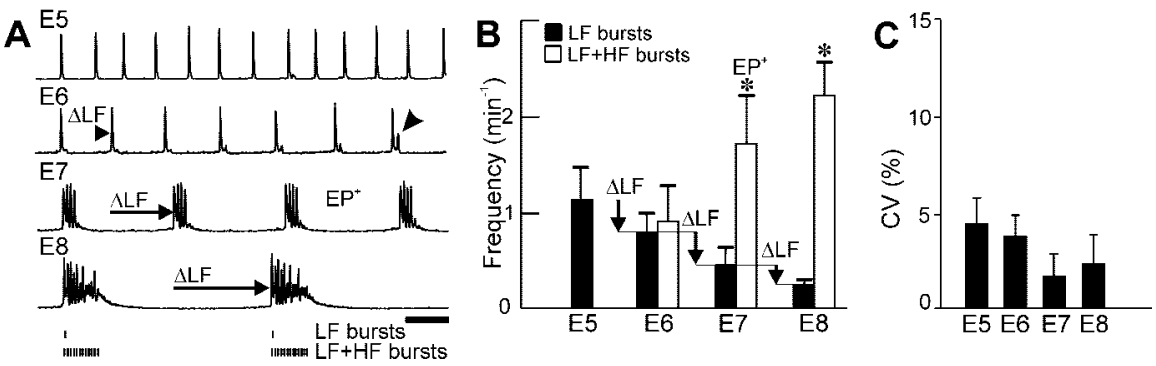

Figure 1. Appearance of episodic patterning of activities $\left(\mathrm{EP}^{+}\right)$: transition from $\mathrm{LF}$ primordial activity. Central pattern generators for $L F$ and episodes are identified by recording neuronal activities after isolation of the hindbrain in vitro. $A$, Integrated facial neurograms recorded at different developmental stages (E5-E8) show a progressive decrease ( $\Delta \mathrm{LF}$; horizontal arrows) in the frequency of $L F$ bursts initiated before $\mathrm{E} 6$ and maintained thereafter. $B$, The $E P^{+}$pattern is identified by the significant difference ${ }^{*}$ ) between the frequency of $L F$ bursts (black bars) and that of LF $+H F$ bursts (empty bars). Note the exclusive presence of $L F$ bursts at $\mathrm{E} 5$ and the emergence ( $A$, arrowhead on the $\mathrm{E} 6$ trace) of HF bursts at E6. C, Regularity of rhythm generation, measured by the $\mathrm{CV}$ of inter-LF burst interval, is maintained during development. Scale bar, $1 \mathrm{~min}$.

corresponding to the desired heterotopic site of insertion of the graft was created using tungsten needles. The graft was then moved into place, the right or left placement of the ectoderm being maintained or inverted in the host embryo, and the egg resealed. For experiments in which $\mathrm{r} 1$ was grafted in place of $\mathrm{r} 3$, HH9 donor embryos were used to ensure that $\mathrm{r} 1$ and $\mathrm{r} 3$ would be similar in size. After grafting, eggs were reincubated for $\sim 2 \mathrm{hr}$ before further isolation of segments and segment pairs. Isolations were made by excising both the immediately rostral and caudal pairs of rhombomeres as described previously (Fortin et al., 1999). The isolation procedure results in an "island" of rhombomere tissue with no connections either anteriorly or posteriorly with the remaining regions of neural tube. These islands round up at their cut surfaces to form ovoid vesicles. The eggs were then sealed again and incubated for either $24 \mathrm{hr}$ (for whole-mount in situ hybridization; see below) or for 5-6 d until the embryos reached E7 (for electrophysiological recordings). Preparations consisting of either whole hindbrains or isolated rhombomere islands were then made by dissecting out the tissues and transferring them to a 2 $\mathrm{ml}$ recording chamber superfused at a rate of $2 \mathrm{ml} / \mathrm{min}$ with a physiological solution composed of the following (in $\mathrm{mM}$ ): $120 \mathrm{NaCl}, 8 \mathrm{KCl}, 0.58$ $\mathrm{NaH}_{2} \mathrm{PO}_{4}, 1.15 \mathrm{MgCl}_{2}, 1.26 \mathrm{CaCl}_{2}, 21 \mathrm{NaHCO}_{3}, 30$ glucose, aerated with carbogen $\left(5 \% \mathrm{CO}_{2}, 95 \% \mathrm{O}_{2}\right), \mathrm{pH} 7.3$, at $30^{\circ} \mathrm{C}$ (Fortin et al., 1999).

Plasmid constructs and electroporation. A Krox20 expression plasmid, pCA $\beta$-mKrox 20 , was constructed by subcloning a ClaI/NotI sequence containing the $1.4 \mathrm{~kb}$ full-length sequence of $m$ Krox 20 into the pCA $\beta_{\text {IRES }}^{\text {eCMV }}$ GFP6 plasmid. The $m$ Krox 20 sequence was excised from the pSlax-mKrox 20 adaptor plasmid usually used for cloning into retroviral vectors. The internal ribosomal entry site (IRES) in $\mathrm{pCA} \beta_{\text {IRES }}^{\text {eCMV }}$ GFP6 is not active, and therefore only $m$ Krox 20 is transcribed in electroporated cells. The activity of this construct was tested by in situ hybridization. The activity of the CA $\beta-m G F P 6$ reporter plasmid was verified by green fluorescent protein (GFP) fluorescence $\sim 6-8 \mathrm{hr}$ after electroporation. An equimolar solution of $p C A \beta-m K r o x 20$ and $p C A \beta-m G F P 6$ at concentrations of $0.5 \mu \mathrm{g} / \mu \mathrm{l}$ was pressure injected into the lumen of the neural tube through glass capillaries (tip diameter, $\sim 10$ $\mu \mathrm{m}$ ) inserted through the roof plate at the 1-2 somite level. The DNA was diluted in PBS with 1.5\% Fast Green to make the DNA solution visible. Electroporation was performed by delivering four to six square pulses (10 $\mathrm{V}$ and $50 \mathrm{msec}$ ) with a pulse-isolated stimulator (Digitimer, Hertfordshire, UK) through anodal and cathodal silver wire (diameter, $1 \mathrm{~mm}$ ) electrodes placed $\sim 1.5 \mathrm{~mm}$ apart on either side of the embryo at the $\mathrm{r} 1 / \mathrm{r} 2$ or $\mathrm{r} 4$ level. Polarity of the current could be reversed or not so as to produce bilateral (data not shown) or unilateral penetration of the plasmids. Control embryos were electroporated with the GFP plasmid only. Electroporated donor embryos destined to grafting experiments were reincubated for $1-2 \mathrm{hr}$ before being prepared (as above).

Electrophysiology. Nerve recording techniques have been reported previously (Fortin et al., 1995). The proximal root of a motor nerve was aspirated into a suction electrode connected to a high gain AC amplifier
(Grass P511; Grass Instruments, Quincy, MA). Amplified neurograms filtered using a bandwidth $(3 \mathrm{~Hz}$ to $3 \mathrm{kHz})$ were rectified and integrated through an analog integrator (Grass 7P3B; Grass Instruments) with a time constant of $50 \mathrm{msec}$. Upward deflections of the rectified, integrated neurogram corresponding to burst discharges of the nerves were acquired using the Acquis1 software package (developed by G. Sadocq, Centre National de la Recherche Scientifique, Gif-sur-Yvette, France) and automatically detected using a threshold device.

Anatomy. In situ hybridization with digoxigenin (DIG)-labeled and fluorescein isothiocyanate (FITC)-labeled riboprobes for $m$ Krox20 and DIG-labeled riboprobes for $c H o x b 1$ was performed as described previously (Wilkinson, 1992). Embryos were harvested in Howard's Ringer or Tyrode's saline and fixed in $4 \%$ paraformaldehyde at $4{ }^{\circ} \mathrm{C}$ until ready for processing. Endogenous cKrox 20 was detected by hybridizing the embryos with the $m K$ rox 20 probe at $65^{\circ} \mathrm{C}$. DIG-labeled probes were detected using 5-bromo-4-chloro-3-indolyl-phosphate and nitroblue tetrazolium as substrates (blue stain) and FITC-labeled probes using FastRed (red stain). Biocytin-labeled neurons were revealed using signal amplification with the ABC method (Vectastain Elite ABC kit PK6100; Vector Laboratories, Burlingame, CA) and standard diaminobenzidine procedure.

Assessment of the rhythm regularity. A modal distribution of inter-burst intervals shorter than $15 \mathrm{sec}$ corresponding to bursts generated at high frequency (HF bursts) indicated an episodic patterning of activity. The episodic pattern $\left(\mathrm{EP}^{+}\right)$has been validated statistically (Mann-Whitney $U$ test) by rejection of the null hypothesis that the medians for both frequency of LF bursts (longer than $15 \mathrm{sec}$ ) (Fig. 1A, LF burst marks under E8 neurogram) and that of the overall LF bursts and HF bursts production (Fig. $1 A, \mathrm{LF}+\mathrm{HF}$ bursts marks under E8 neurogram) were equal $(p<0.01)$ (Fig. $1 B$, asterisks on histograms). In this way, $\mathrm{EP}^{+}$and $\mathrm{EP}^{-}$patterns can be discriminated from pacemaker mechanisms controlling the regularity of activities otherwise quantified by measurement of the mean coefficient of variation $(\mathrm{CV}, \mathrm{SD} /$ mean) of inter-LF burst intervals (Fig. 1C). For preparations having an activity exclusively composed of LF bursts, only the frequency of LF bursts (black bars) is presented on summary histograms. In the text and Table 1, data are expressed as mean $\pm \mathrm{SD}$, and the figure error bars represent SD.

\section{Results}

\section{$\mathrm{EP}^{+}$identification}

Electrophysiological recordings of the facial nerve in whole hindbrain preparations at E5-E8 (Fig. 1A) showed that the lowfrequency generation of single-burst discharges (LF bursts) recorded at E5 begins to change during E6 when additional bursts are produced at high frequency (HF bursts) after LF bursts to form an episode of activity (LF+HF bursts). This episodic burst production at E6 is preceded by (E5-E6) and later associated with (E7-E8) a decrease of the frequency at which LF bursts are produced (Fig. $1 A, B, \Delta \mathrm{LF}$ ). The regularity of the episodic rhythm, 
A

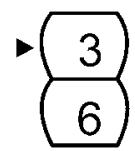

heterotopic odd, posterior shift

B

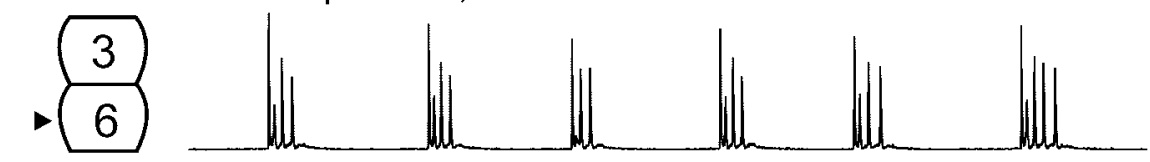

C
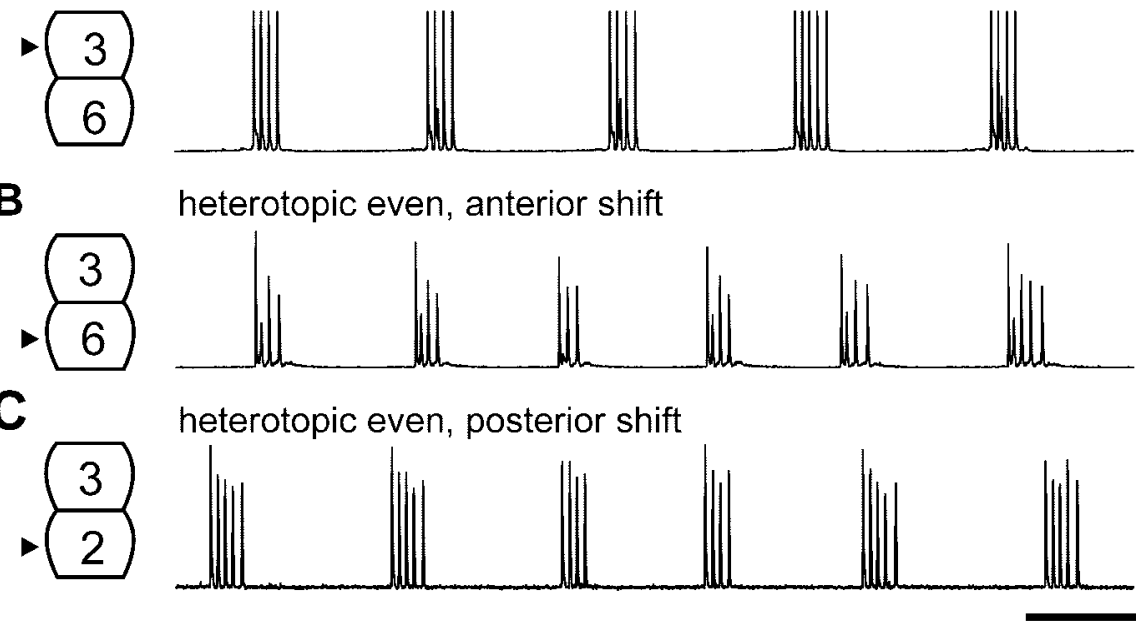

heterotopic even, anterior shift

heterotopic even, posterior shift
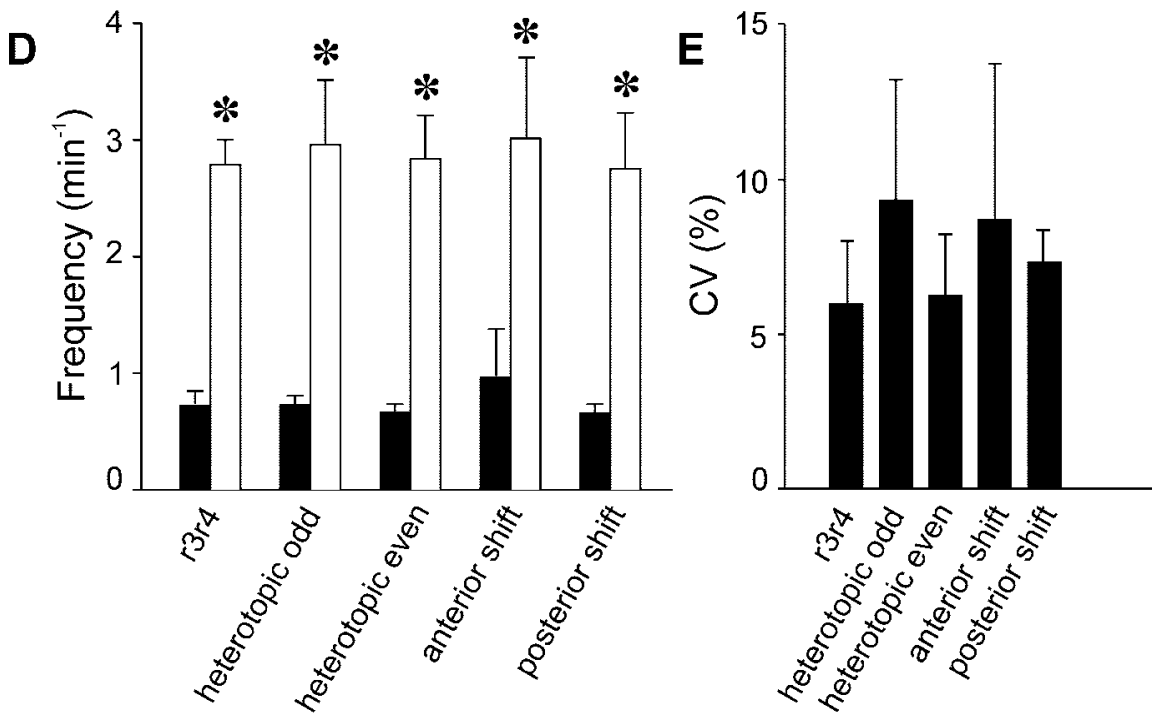

Figure 2. Anterior-odd rhombomeric code for the induction of $\mathrm{EP}^{+}$. Integrated glossopharyngeal $(A, B)$ or trigeminal $(C$ neurograms obtained after heterotopic grafting and isolation. Transplantations of the odd $r 3$ (in r 5 position; $A$, arrowhead) and of the even $r 6$ (in $r 4$ position; $B$, arrowhead) or $r 2$ (in $r 4$ position; $C$, arrowhead) lead to $r 3 \mathrm{r} 6$ or $r 3 \mathrm{r} 2$ preparations showing an episodic patterning similar to that obtained from the normal configuration $r 3 r 4 . D, E$, Summary histograms of the frequencies of $L F$ bursts and $\mathrm{LF}+\mathrm{HF}$ bursts ( $D$, filled and empty bars, respectively) and of $\mathrm{CV}(E)$ obtained after pooling preparations according to the heterotopic status of either odd $(\mathrm{r} 3, \mathrm{r} 5)$ or even $(\mathrm{r} 2, \mathrm{r} 4, \mathrm{r6})$ rhombomeres (detailed in Table 1$)$ and the anterior or posterior status of the displacement along the neuroaxis (anterior shift and posterior shift) of rhombomeres, whatever their parity (detailed in Table 1). In all cases, an $\mathrm{EP}^{+}$pattern comparable with that of the normal $\mathrm{r} 3 \mathrm{r} 4$ pair resulted. Surgical isolation, shift, and grafting of rhombomeres do not interfere with the development of the $\mathrm{EP}^{+}{ }^{+}$in artificial rhombomere pairs in which the odd rhombomere is in contact with the anterior edge of the even rhombomere. Scale bar, $1 \mathrm{~min}$.

estimated from the low values of CV of inter-episode time intervals (Fig. $1 C, \mathrm{CV}$ ), remains high during this process. Thus, we could ascertain the ability for a preparation to produce episodes $\left(\mathrm{EP}^{+}\right)$from the significant difference $(p<0.01)$ (Fig. $1 B$, asterisk) between frequency values of LF and LF+HF burst discharges recorded at E7, a developmental stage at which the hindbrain has been found to be $\mathrm{EP}^{+}$in $100 \%$ of cases (Table 1 ). In $\mathrm{EP}^{+}$preparations comprising single odd rhombomeres or odd-even pairs of rhombomeres (e.g., r3r4) (Table 1) (Fortin et al., 1999), an episodic pattern was observed in $80 \%$ of cases at E6 (16 of 20) but in $0 \%$ at $\mathrm{E} 5$, demonstrating that the rhombomere isolation procedure does not interfere with the kinetics of activity maturation. In contrast, when recording from preparations comprising single even rhombomeres or even-odd pairs of rhombomeres (e.g., r4r5) (Table 1) (Fortin et al., 1999), the episodic activity does not appear at E6 and is absent at $\mathrm{E} 7\left(\mathrm{EP}^{-}\right)$. At E7, all EP ${ }^{-}$preparations retained an immature elevated frequency of LF bursts, lacking the characteristic $\Delta \mathrm{LF}$ of $\mathrm{EP}^{+}$segments (Table 1, compare values for r4r5 at E6 and E7). At later stages of development, $\mathrm{EP}^{-}$preparations tended to develop the episodic pattern. Indeed, the occurrence of $\mathrm{EP}^{+}$noted in $10 \%$ ( 2 of 17) of the cases at E7 began to increase at E8 (37\%; 3 of 8 cases) reaching significance $\left(63 \% ; 5\right.$ of 8 cases; $\chi^{2}, p<$ $0.01)$ at E9. Thus, $\mathrm{EP}^{-}$preparations seem considerably delayed in the developmental program leading to episodic patterning, which is tightly linked to the development of LF.

\section{A rhombomeric code enabling development of episodic bursts} The $\mathrm{EP}^{+}$pattern could be recorded from the facial motor root ( $\mathrm{r} 4)$ in all cases where r5 was grafted in heterotopic position anterior to the even rhombomere ( $\mathrm{r} 5{ }^{*} \mathrm{r} 4$ ) (Table 1 ). The $\mathrm{EP}^{+}$pattern was also recorded in one case where $\mathrm{r} 4$ was grafted posterior to r5. Episodic activities were comparable with those obtained with normal r3r4 segments.

Although episodic rhythm generation at the facial level predominates in the intact hindbrain (Fortin et al., 1999), EP ${ }^{+}$ was also obtained from the glossopharyngeal motor root (r6) in normal r5r6 preparations (Table 1) or when $\mathrm{r} 3$ had been grafted into the $\mathrm{r} 5$ position (Fig. $2 \mathrm{~A}$ ) or $\mathrm{r} 6$ into the $\mathrm{r} 4$ position (Fig. $2 \mathrm{~B}$ ). $\mathrm{EP}^{+}$was also produced by the trigeminal motor root $(\mathrm{r} 2)$ when $\mathrm{r} 5$ was grafted anterior to $\mathrm{r} 2$ (data not shown) (Table 1) or $\mathrm{r} 2$ caudal to r3 (Fig. 2C). As for the facial nerve, the trigeminal was $\mathrm{EP}^{-}$in preparation where r1 was left in normal contact with the even rhombomere (r1r2) (Table 1). In contrast, an $\mathrm{EP}^{-}$identical to that obtained with $\mathrm{r} 4$ alone (Fig. $3 \mathrm{~A}$ ) was obtained by grafting $\mathrm{r} 1$ anterior to $\mathrm{r} 4$ (Fig. 3C) or by grafting $\mathrm{r} 3$ posterior to $\mathrm{r} 4(p=0.147)$.

Altogether, the graft configurations match an "anterior odd" rhombomeric code for $\mathrm{EP}^{+}$patterning: all rhombomere pairs in which the odd rhombomere $\mathrm{r} 3$ or $\mathrm{r} 5$ (but not $\mathrm{r} 1$ ) is in contact with the anterior edge of the even rhombomere produce the $\mathrm{EP}^{+}$ pattern (Fig. $2 D$ ) with a low CV (Fig. $2 E$ ), regardless of which rhombomere had been displaced or whether it had been displaced anteriorly or posteriorly along the neuraxis (Fig. 2, Table 1).

\section{Development of the episodic network is induced by Krox20 electroporation in $\mathbf{r} 4$}

To identify a possible role of Krox20, which is expressed in $\mathrm{r} 3$ and $\mathrm{r} 5$ but not $\mathrm{r} 1$, and which is known to specify aspects of $\mathrm{r} 3$ and $\mathrm{r} 5$ character (Giudicelli et al., 2001), we followed a gain-of-function 
strategy. First, we wanted to see whether ectopic expression of Krox20 in r4 would induce $\mathrm{EP}^{+}$when the rhombomere is isolated from both $\mathrm{r} 3$ and $\mathrm{r} 5$. Normal isolated $\mathrm{r} 4$ is $\mathrm{EP}^{-}$(Fig. $3 \mathrm{~A}$ ), indicating that a prolonged odd-even interaction is required to develop an episodic network. However, when Krox20 is ectopically expressed from $\mathrm{HH} 10$ in $\mathrm{r} 4$, the isolated rhombomere developed $\mathrm{EP}^{+}$(Fig. 3 B, Table 1). As demonstrated by Giudicelli et al. (2001), ectopic expression of Krox20 in r4 initiates a program that attempts to convert cells to an $\mathrm{r} 3$ or $\mathrm{r} 5$ identity generating mixed cellular populations. Assuming that ectopic Krox20 has the same outcome in our hands, it is likely that the production of an indeterminate mix of $\mathrm{r} 3, \mathrm{r} 5$, and $\mathrm{r} 4$ cells in the targeted territory confers properties sufficient to induce formation of an episodic generator.

\section{Krox 20-expressing $\mathrm{r} 1$ exerts a $\mathrm{EP}^{+}$-} inducing influence on $\mathbf{r} 4$

To further explore the role of Krox20, we next combined the electroporation procedure with heterotopic grafting to form abnormal rhombomere pairs. We made r1r4 preparations (Fig. 4) because $\mathrm{r} 1$ does not normally express Krox20 or any of the Hox genes expressed in posterior rhombomeres (Lumsden and Krumlauf, 1996). As shown above, the $\mathrm{r} 1 \mathrm{r} 4$ preparations are $\mathrm{EP}^{-}$in all cases (Fig. 3C, Table 1). After electroporation of donor embryos with Krox20 and GFP plasmids, we grafted $\mathrm{r} 1$ in place of host $r 3$, followed by microsurgical isolation of the rhombomere pair. In these preparations, the $\mathrm{r} 1$ territory expressed both Krox20 and GFP or GFP alone (Fig. 4) (data not shown). All Krox20expressing r1r4 preparations (Fig. 3D) and none of those expressing GFP only developed $\mathrm{EP}^{+}$(Table 1). Robustness of induction is shown by the ability to obtain the $\mathrm{EP}^{+}$ pattern even when restricting ( 2 of 5 cases) Krox 20 expression to one side of the donor $\mathrm{r} 1$ segment by unilateral electroporation (Fig. 4). Altogether, the results obtained by electroporation suggest that Krox20 expression in $\mathrm{r} 1$ is sufficient to drive a specific AP interaction leading to episode generation in $\mathrm{r} 4$.

\section{AP reversal of $r 4$, but not $r 3$, impairs development of the rhythm generator}

To identify which of the two rhombomeres in the $\mathrm{r} 3 \mathrm{r} 4 \mathrm{EP}^{+}$preparation exerts directional control on the other, we inverted the AP polarity of each rhombomere independently. Inversion of $\mathrm{r} 3$ [Table 1, flipped (f) (r3)r4] did not change the $\mathrm{EP}^{+}$outcome (Fig. $5 E$, compare $\mathrm{a}, \mathrm{b})$, showing that AP polarity of $\mathrm{r} 3$ is not critical. This is consistent with the view that $\mathrm{r} 3$ acts as a homogenous source of $\mathrm{EP}^{+}$-inducing activity. However, reversal of $\mathrm{r} 4$ resulted in dramatically altered development of the rhythm (Fig. 5C). First, an $\mathrm{EP}^{-}$pattern resulted [Table 1, r3f(r4)]. Second, the rhythm became irregular as indicated by an increased CV (from
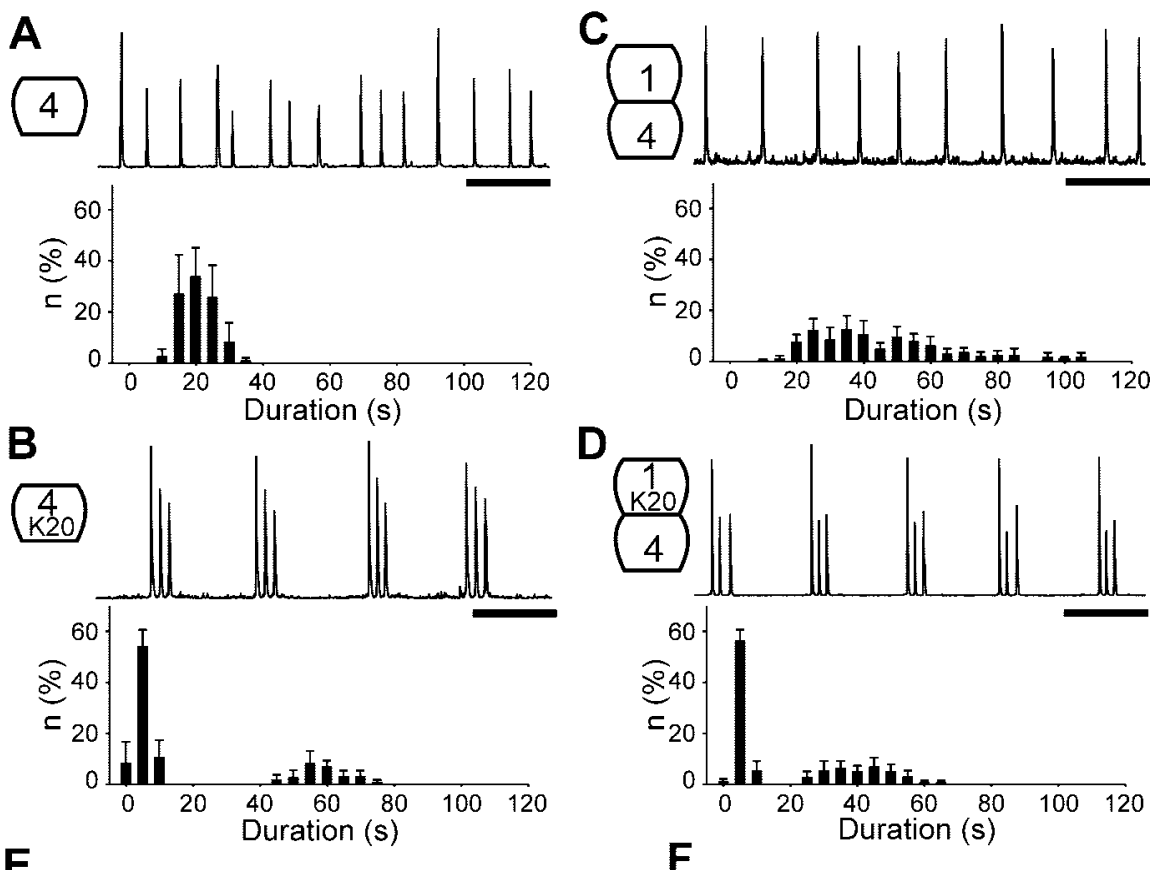

$F$

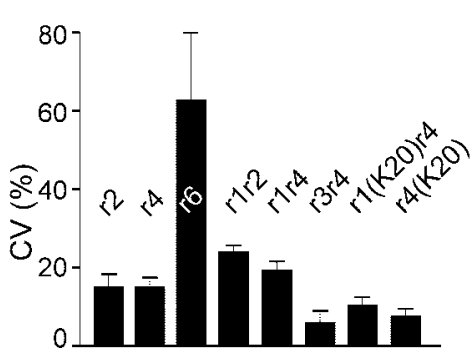

Figure 3. Electroporation of Krox20 confers the $\mathrm{EP}^{+}$pattern to the $\mathrm{r} 4$ and $\mathrm{r} 1 \mathrm{r} 4 \mathrm{EP}^{-}$segments. Integrated neurograms (top) and corresponding compound distribution of interburst interval durations (bottom; $\mathrm{n} \%$ ordinates; duration abscissae) recorded at

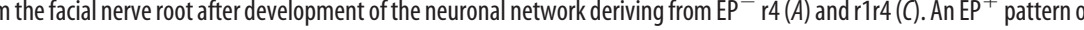
Krox20 induces $\mathrm{EP}^{+}$in $\mathrm{r} 4$ and $\mathrm{r} 1 \mathrm{r} 4$ (asterisks; compare with the normal configuration, $\mathrm{r3r}$ ). F, CV is not significantly affected in these experiments and is particularly large for r6. Scale bar, $1 \mathrm{~min}$.

0.05 to 0.23$)$. This was not observed after reversal of the entire r3r4 (see Fig. 7C) [Table 1, f(r3r4)] that led to normal $\mathrm{EP}^{+}$.

Mechanisms responsible for the regularity of the rhythm would be distinct from those generating episodes because grafting $\mathrm{r} 3$ caudal to $\mathrm{r} 4$ produces a regular bursting pattern $(\mathrm{CV}, 0.12)$ but no episodes (Fig. 5D; Table 1, r4r3*). Altogether, these experiments show that AP reversal of $r 4$, but not $r 3$, alters the functional organization of the rhythmogenic neuronal network. This suggests that in the r3r4 pair, the rhythmogenic network is located in $r 4$, not $r 3$, whereas $r 3$, not $r 4$, is the source of an interrhombomeric influence that is necessary for it to become $\mathrm{EP}^{+}$ and function appropriately.

\section{$\mathrm{AP}$ reversal of $\mathrm{r} 4$ in $\mathrm{r} 4 \mathrm{r} 5$ preparations produces $\mathrm{EP}^{+}$}

Our findings with $\mathrm{r} 3 \mathrm{r} 4$ preparations (Fig. $5 C, D$ ) indicate that reversal of $\mathrm{r} 4$ disrupts the rhombomeric code enabling development of episodic bursts. These results suggest that even if a "contact with the anterior odd rhombomere" position along the neuraxis is preserved, the $\mathrm{EP}^{+}$phenotype also requires correct AP polarity of the even rhombomere. We further investigated this hypothesis, starting from the $\mathrm{EP}^{-}$pair $\mathrm{r} 4 \mathrm{r} 5$ (Figs. $6,7 \mathrm{D}$ ), a good 
model to investigate how $\mathrm{EP}^{+}$potentialities in the other Krox20expressing rhombomere, $\mathrm{r} 5$, interact with $\mathrm{r} 4$ in the absence of $\mathrm{r} 3$ (Fig. 6, compare a, d). In the r $4 \mathrm{r} 5$ preparation, we inverted the AP polarity of the $\mathrm{r} 4$ segment (Figs. $6 C, 7 E$ ) or of the entire $\mathrm{r} 4 \mathrm{r} 5$ region (Figs. $6 B, 7 F$ ). Rhombomere 4 reversal, bringing its anterior edge into contact with $\mathrm{r} 5$, produced $\mathrm{EP}^{+}$activity, which was not detected when reversing the AP orientation of entire $\mathrm{r} 4 \mathrm{r} 5$ pair (Fig. $6 \mathrm{~B}$, compare $\mathrm{c}$ and $\mathrm{b}$ in $E$ ). Finally, the $\mathrm{EP}^{+}$was fully restored by grafting $\mathrm{r} 5$ anterior to $\mathrm{r} 4$ (Fig. $6 \mathrm{D}$ ) or $\mathrm{r} 4$ posterior to $\mathrm{r} 5$ (data not shown) (Table 1). These experiments failed to reveal any $\mathrm{EP}^{+}$-repressing (Fig. $6 C, E$ ) or $\mathrm{EP}^{+}$-promoting (Fig. 6A,E) effects of $\mathrm{r} 5$ in its normal (caudal) situation. However, $\mathrm{r} 5$ shows the same property as $\mathrm{r} 3$ to induce formation of $\mathrm{EP}^{+}$activity provided it is in contact with the anterior border of $\mathrm{r} 4$. Regularity of the rhythm is altered in $\mathrm{r} 4 \mathrm{r} 5$ preparations when rendered $\mathrm{EP}^{+}$ by reversal of the AP polarity of $\mathrm{r} 4$ or when preserving $\mathrm{EP}^{-}$after $\mathrm{AP}$ inversion of the entire $\mathrm{r} 4 \mathrm{r} 5$ region (Fig. $6 \mathrm{~F}$, compare $\mathrm{CV}$ in a and $b, c$ and $d$ ), confirming that distinct mechanisms control episode formation and the regularity of their recurrence.

\section{Discussion}

Our results help to understand development of a parafacial rhythmogenic system and allow us to propose a novel functional

Table 1. Characterization of $\mathrm{EP}^{+}$and $\mathrm{EP}^{-}$preparations

\begin{tabular}{|c|c|c|c|}
\hline Preparations & $n$ & LF bursts & $\mathrm{LF}+\mathrm{HF}$ bursts \\
\hline \multicolumn{4}{|l|}{$E P^{-}$} \\
\hline E5 hindbrain & 7 & $1.15 \pm 0.34$ & id. \\
\hline E6 hindbrain & 5 & $0.80 \pm 0.20$ & $0.92 \pm 0.21, \mathrm{NS}$ \\
\hline $\mathrm{r} 2$ & 3 & $2.66 \pm 1.12$ & id. \\
\hline $\mathrm{r} 4$ & 4 & $2.38 \pm 0.28$ & id. \\
\hline r6 & 5 & $2.15 \pm 0.66$ & id. \\
\hline $\mathrm{r} 2 \mathrm{r3}$ & 3 & $1.11 \pm 0.27$ & id. \\
\hline r4r5 (at E6) & 5 & $2.25 \pm 1.01$ & id. \\
\hline $\mathrm{r} 4 \mathrm{r5}$ & 9 & $2.20 \pm 0.67$ & id. \\
\hline $\mathrm{r} 1 \mathrm{r} 2$ & 2 & $1.42 \pm 0.49$ & id. \\
\hline r1r4 & 7 & $1.26 \pm 0.57$ & id. \\
\hline r1(GFP)r4 & 3 & $1.10 \pm 0.23$ & id. \\
\hline$f(r 4 r 5)$ & 9 & $1.21 \pm 0.35$ & $1.96 \pm 1.03, \mathrm{NS}$ \\
\hline$r 3 f(r 4)$ & 4 & $1.28 \pm 0.20$ & $1.64 \pm 0.36, \mathrm{NS}$ \\
\hline$r 4 r 3^{*}$ & 2 & $2.02 \pm 0.12$ & $2.21 \pm 0.27, \mathrm{NS}$ \\
\hline \multicolumn{4}{|l|}{$\mathrm{EP}^{+}$} \\
\hline E7 hindbrain & 21 & $0.45 \pm 0.21$ & $1.75 \pm 0.51$ \\
\hline E8 hindbrain & 8 & $0.24 \pm 0.06$ & $2.27 \pm 0.35$ \\
\hline $\mathrm{r} 3 \mathrm{r} 4$ & 6 & $0.72 \pm 0.08$ & $2.78 \pm 0.21$ \\
\hline$r 5 r 6$ & 4 & $0.79 \pm 0.10$ & $2.55 \pm 0.24$ \\
\hline$r 5^{*} r 4$ & 3 & $1.10 \pm 0.51$ & $3.46 \pm 0.33$ \\
\hline Heterotopic odd & 5 & $0.72 \pm 0.14$ & $2.96 \pm 0.54$ \\
\hline Heterotopic even & 4 & $0.67 \pm 0.12$ & $2.84 \pm 0.39$ \\
\hline Anterior shift & 5 & $0.96 \pm 0.41$ & $3.02 \pm 0.69$ \\
\hline Posterior shift & 4 & $0.66 \pm 0.12$ & $2.75 \pm 0.49$ \\
\hline $\mathrm{r} 4(\mathrm{~K} 20)$ & 4 & $0.84 \pm 0.15$ & $3.01 \pm 0.38$ \\
\hline $\mathrm{r} 1(\mathrm{~K} 20) \mathrm{r} 4$ & 5 & $1.05 \pm 0.32$ & $2.85 \pm 0.81$ \\
\hline$f(r 3) r 4$ & 7 & $0.75 \pm 0.13$ & $2.95 \pm 0.62$ \\
\hline$f(r 3 r 4)$ & 7 & $0.72 \pm 0.14$ & $3.11 \pm 0.94$ \\
\hline$f(r 4) r 5$ & 5 & $0.96 \pm 0.62$ & $3.13 \pm 0.82$ \\
\hline
\end{tabular}

Summary table of the values of LF burst and LF $+\mathrm{HF}$ burst frequencies (minute ${ }^{-1}$ ) measured on the different preparations at $\mathrm{E}$. Anteroposterior position of rhombomeres in rhombomere pairs is indicated from left to right (e.g., r $4 \mathrm{r} 5$-r4 anterior to $\mathrm{r} 5$ ). An asterisk to the right of a rhombomere indicates that the rhombomere has been heterotopically grafted (e.g. $r 4 \mathrm{r} 3^{*}-\mathrm{r} 3$ grafted in heterotopic $r 5$ position). The f preceding rhombomeres in brackets indicates their flipped anteroposterior orientation. GFP or K20 in a bracket to the right of a rhombomere indicates that this rhombomere was targeted by electroporation of the sole GFP or the GFP and Krox20 expression vectors, respectively. Heterotopic odd and even refer to compound measurements pooling, respectively, $r 3^{*} \mathrm{r} 6(n=1), r 5^{*} \mathrm{r} 4$ $(n=3)$, and $r 5^{*} \mathrm{r} 2(n=1)$ and $\mathrm{r} 3 \mathrm{r} 6^{*}(n=1), \mathrm{r} 3 \mathrm{r}^{*}(n=2)$, and $\mathrm{r} 5 \mathrm{r} 4^{*}(n=1)$ preparations. Anterior and posterior shift refer to compound measurements obtained pooling, respectively, $r 3 r^{*}(n=1), r 5^{*} \mathrm{r} 4(n=3)$, and $r 5^{*} \mathrm{r2}(n=$ 1) and $\mathrm{r}^{*} \mathrm{r} 6(n=1), \mathrm{r} 3 \mathrm{r} 2^{*}(n=2)$, and $\mathrm{r} 5 \mathrm{r} 4^{*}(n=1)$ preparations. id., Idem; NS, no significant difference between frequency values of $L F$ bursts and $L F+H F$ bursts.
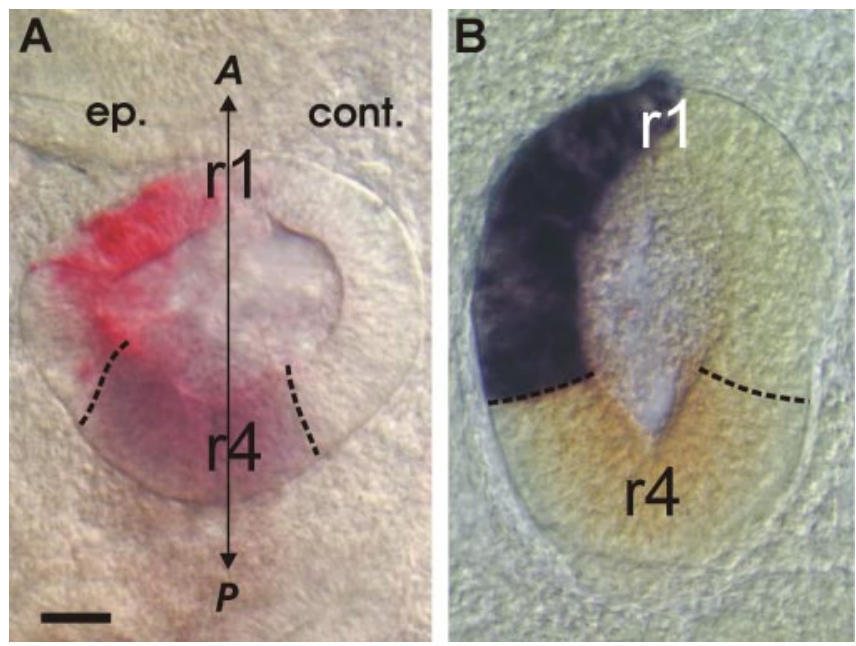

Figure 4. Whole-mount $\mathrm{r}$ (K20) $\mathrm{r} 4$ islands $24 \mathrm{hr}$ after electroporation grafting and isolation. $A, B$, Two examples of rhombomere islands (dorsal views) produced by heterotopic grafting in $\mathrm{r} 3$ position of $\mathrm{r} 1$ territories taken from donor embryos that had been submitted to unilateral electroporation of mixed GFP and Krox20 expression plasmids at the $r 1$ level, before engraftment and isolation of the $11 r 4$ island. Note the overt healing at boundaries ( $A$ and $B$, dotted lines) separating $\mathrm{r} 1$ anterior and $\mathrm{r} 4$ posterior and the ovoid aspect taken by the isolated rhombomere pairs. Forced Krox20 expression (red in $A$, dark blue in $B$ ) is visible on the electroporated side (ep.) on the left of the medial axis ( $A$, vertical line) but not on the control side (cont.; right) of the $r 1$ territory. Krox20 expression is confined within $\mathrm{r} 1(A, B)$, and a sharp AP limit of expression is visible on the ep. side in $B$, whereas endogenous bilateral Hoxb1 expression (blue in $A$, not probed in $B$ ) is restricted to $r 4$. The activity produced by this rhombomeric configuration is illustrated in Figure 3 D. A, Anterior; P, posterior. Scale bar, $50 \mu \mathrm{m}$.

role for Krox20 in initiating the induction of the episodic generator during a restricted period of development, between $\mathrm{HH} 10$ (time of grafting) and HH15-HH20 (Krox20 downregulation). Krox20 expression starts in $\mathrm{r} 3$ as early as at $\mathrm{HH}$, before the onset of hindbrain segmentation (Nieto et al., 1991; Irving et al., 1996; Giudicelli et al., 2001). However, we show that several hours later, at $\mathrm{HH} 10$, induction of the episodic activity is blocked in a variety of rhombomeric configurations but can be restored by Krox20 electroporation. All even rhombomeres are $\mathrm{EP}^{-}$, although by this stage, their neighboring rhombomeres already express Krox 20 . Hence, there is no early commitment to the production of the episodic pattern. Indeed, all artificial rhombomere pair combinations behave in strict accordance to a "anterior odd" code that either exists normally or can be produced by grafting. Thus, early AP positional value (Guthrie and Lumsden, 1992; Simon et al., 1995; Grapin-Botton et al., 1998; Dupé and Lumsden, 2001) has no obvious influence on the future pattern of rhythmic activities. The processes leading to episodes certainly begin after $\mathrm{HH} 10$ and probably cease with the downregulation of Krox20 expression in r3 at HH15-HH20 (Wilkinson et al., 1989; Schneider-Maunoury et al., 1993, 1997).

Our results indicate the importance of heterochronic development of rhombomeres in the hindbrain by which gene expression, boundary formation, and neurogenesis do not take place at the same time in adjacent rhombomeres. Between HH10 and HH15-HH20, r3 and $\mathrm{r} 5$ display a marked delay compared with even rhombomeres in the timing of neuronal differentiation and axonal outgrowth (Lumsden and Keynes, 1989; SchneiderMaunoury et al., 1997; Giudicelli et al., 2001). We now show that with respect to the rhythm regularity and episodic patterning of activities, susceptibility to AP reversal at HH10 is restricted to 4 . Therefore, heterochrony of neurogenic processes at the parafacial level of the neuraxis allows the simultaneous neuronal differentia- 


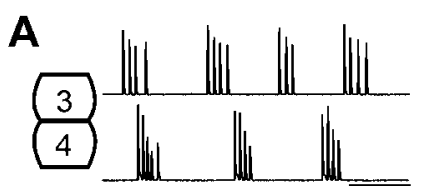

B
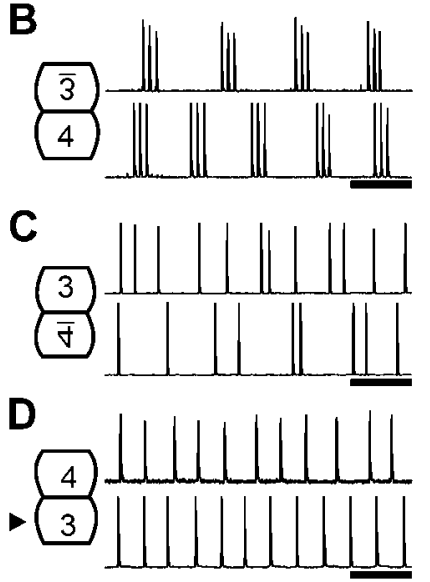

E

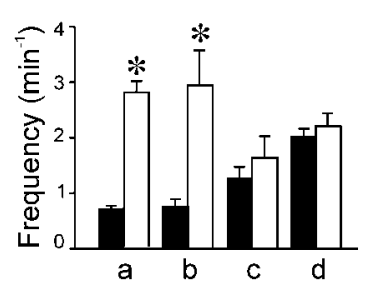

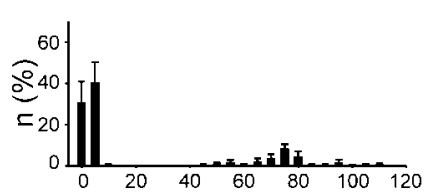
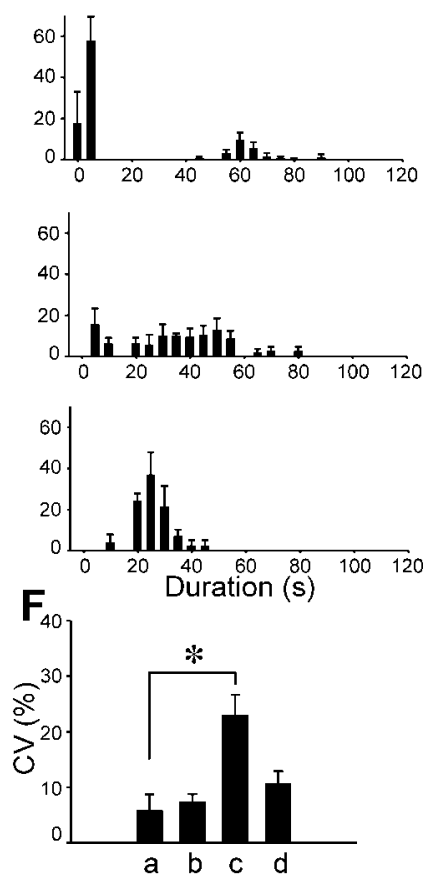

Figure 5. Anteroposterior orientation of $r 4$, but not $r 3$, is required for the development of a stable rhythm generator. $A-D$, Two examples (superposed traces) of integrated motor activity (left) recorded from distinct rhombomere pair preparations (left schematic) and compound histograms of the corresponding distribution of interburst interval duration (right) recorded from the facial nerve. $A, B$, Episodic patterning is present in $r 3 \mathrm{r} 4$ (normal configuration) and $\mathrm{r} 3 \mathrm{r} 4$ after AP reversal of $r 3(B)$, absent $(C, D)$ in $r 3 r 4$ after AP reversal of $r 4(C)$, and in $r 4 r 3$ after heterotopic transplantation of $\mathrm{r} 3$ (in $\mathrm{r} 5$ position; $D$, arrowhead). $E$, $F$, Summary histogram of the frequency of LF bursts and LF + HF bursts ( $E$, filled and empty bars, respectively) and of $C V(F)$ of the different preparations indicated by their lettering in the figure. Reversal of $r 4$ eliminates regularity of the rhythm as indicated by significantly higher mean $\mathrm{CV}$ in $F$ (compare c, a). Note also in $E$ that modifying the relative position of $\mathrm{r} 3$ with respect to anteroposterior polarity of $\mathrm{r} 4$ abolishes (in c and d) the development of episodes (a and b). Scale bar, 1 min.

tion in $\mathrm{r} 4$ and Krox20 expression in r3, a feature that seems important to the establishment of mature rhythmogenic properties.

\section{Krox20 in $\mathrm{r} 3$ exerts an $\mathrm{EP}^{+}$-inductive role after $\mathrm{HH} 10$}

It is unlikely that Krox 20 effects the induction of $\mathrm{EP}^{+}$in $\mathrm{r} 4$ by the generation of some specific subtype of $\mathrm{r} 3$ neuron with posteriorly directed processes, because AP inversion of $\mathrm{r} 3$ does not affect the induction of $\mathrm{EP}^{+}$. Indeed, other studies show that Krox20 inhibits (rather than stimulates) neurogenesis and neuronal differentiation (Giudicelli et al., 2001).

In contrast, because r3, r5, and Krox20-misexpressing rhombomeres were equally effective, Krox20 induction of the episodic activity most probably depends on its role in specifying $r 3 / \mathrm{r} 5$ identity and their ensuing properties. Hence, non-cell-autonomous mechanisms such as those extending the Krox20 expression domain at the expense of $\mathrm{r} 2$ in the normal hindbrain, or $\mathrm{r} 4$ after Krox20 electroporation (Giudicelli et al., 2001), are possibly involved. Rhombomere boundaries are potentially important for the action of inductive signals on developing neurons in an adjacent rhombomere. Once expressed, Krox20 controls the expression of several gene products contributing to the establishment of the $\mathrm{r} 3 / \mathrm{r} 4$ boundary (Theil et al.,
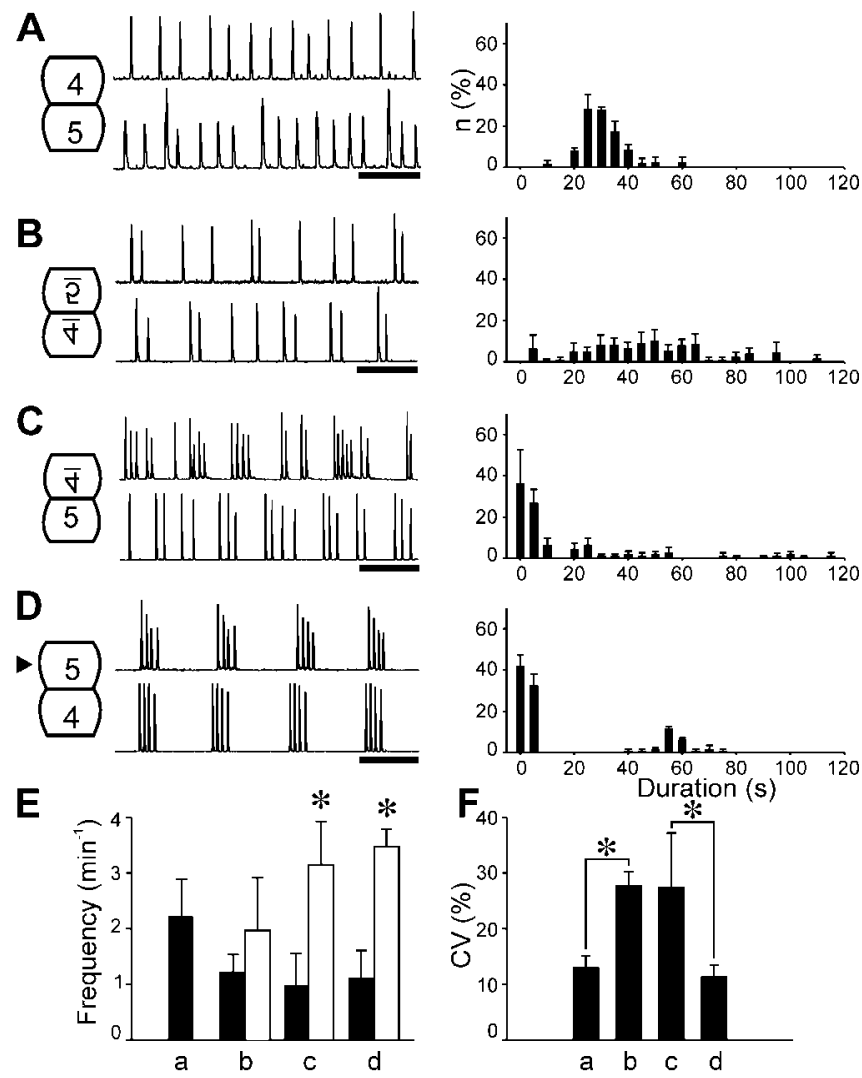

Figure 6. Anteroposterior reversal of $r 4$ produces the development of an episodic generator in $r 4 r 5$. A-D, Two examples (superposed traces) of integrated motor activity (left) recorded from distinct rhombomere pair preparations (left schematic) and compound histograms of the corresponding distribution of interburst interval duration (right) recorded from the facial nerve. $A, B$, Episodic patterning is absent in $\mathrm{r} 4 \mathrm{r} 5$ ( $A$, normal configuration) and after reversal of the entire $\mathrm{r} 4 \mathrm{r} 5$ pair $(B)$ and is produced $(C, D)$ in $\mathrm{r} 4 \mathrm{r} 5$ after AP reversal of $r 4$ alone $(C)$ and in $r 5 \mathrm{r} 4$ after heterotopic transplantation of $\mathrm{r} 5$ (in $\mathrm{r} 3$ position; $D$, arrowhead). $E$, $F$, Summary histogram of the frequency of LF bursts and LF $+H F$ bursts ( $E$, filled and empty bars, respectively) and of $C V(F)$ of the different preparations. The $E P^{+}$pattern is produced $(E$, asterisks) by modifying the relative position of $\mathrm{r} 5$ with respect to the anteroposterior orientation of $\mathrm{r} 4$ (in c and $\mathrm{d}$ but not in a and $\mathrm{b}$ ). Reversal of $\mathrm{r} 4(B, C)$ also eliminates regularity of the rhythm as indicated by significantly higher mean CVs ( $F$, asterisks). Scale bar, 1 min.

1998; Xu et al., 1999; Mechta-Grigoriou et al., 2000). A target of Krox20, EphA4, encodes a cell surface molecule contributing to cell sorting during boundary formation (Wizenmann and Lumsden, 1997; Xu et al., 1999). Expression of these genes is highly dynamic and might contribute to inter-rhombomeric regulation well after HH10. Thus, signaling initiated by Krox20 expression can control the functional fate of differentiating neurons (Takasu et al., 2002). Signaling initiated by Krox20 expression and leading to the formation of rhombomere boundaries may be important during development of neuronal networks, including rhythm generators (Kullander et al., 2003).

Competence of $\mathbf{r} 4$ to produce the episodic rhythm requires correct anteroposterior polarity with respect to $\mathrm{r} 3$

Our observations on $\mathrm{r} 4$ suggest that differentiating neurons may be the target of signaling from $r 3$. Boundaries between rhombomeres are characterized by enhanced extracellular space preferentially colonized by axons (Lumsden and Keynes, 1989). Thus, one of the potential roles of boundaries is to direct axonal growth within rhombomeres. Interestingly, Krox20 electroporation experiments in chick (Giudicelli et al., 2001) have shown that extending axons of $\mathrm{r} 4$ neurons avoid the territories expressing 


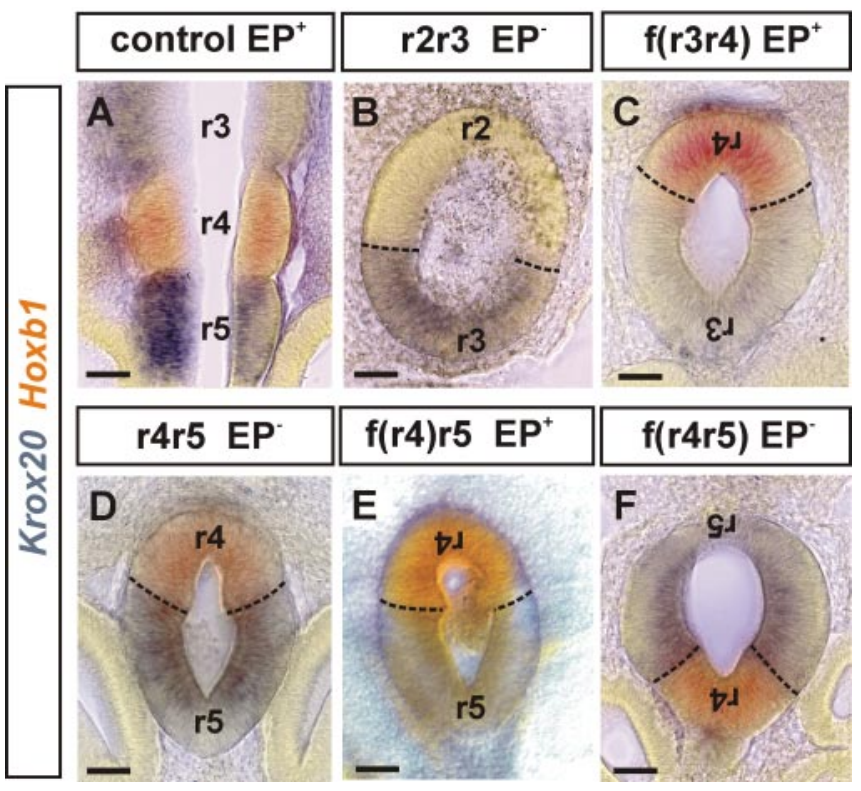

Figure 7. Horizontal sections of preparations, including the anteroposterior reversal of $r 4,24$ hr after surgical manipulation. In situ hybridization for Krox2O (blue) and Hoxb1 (red) in a control hindbrain $(A)$ and in isolated rhombomere island preparations $(B-F)$. Normal configurations, $\mathrm{r} 2 \mathrm{r} 3(B)$ and $\mathrm{r} 4 \mathrm{r} 5(D)$; modified configurations, AP inverted ( $f$ ) pair of segment $\mathrm{r} 3 \mathrm{r} 4$ ( $C$ ) and $\mathrm{r} 4 \mathrm{r} 5$ $(F)$ and flipped $r 4$ within the $r 4 \mathrm{r} 5$ pair $(E)$. In all cases, Hoxb1 expression is preserved in $\mathrm{r} 4$ and Krox20 expression in $\mathrm{r} 3$ and $\mathrm{r} 5$, although episodic patterning is present $\left(\mathrm{EP}^{+}{ }^{+}\right.$in $\left.A, C, E\right)$ or absent $\left(\mathrm{EP}^{-}\right.$in $\left.B, D, F\right)$. Scale bar, $50 \mu \mathrm{m}$.

Krox20 or the patches of ectopic Krox20 expression. Branchial motor neurons are inclined to extend their axons rostrally from odd rhombomeres (e.g., r3) through their anterior (e.g., r2/r3) boundary, whereas crossing their posterior boundaries (e.g., r3/ r4) is avoided. There is a considerable amount of data demonstrating anomalies of this organization of motor neurons when segmental patterns of gene expression are modified (Marshall et al., 1992; Barrow and Capecchi, 1996; Goddard et al., 1996; Studer et al., 1996; Gavalas et al., 1997). The importance of Krox20 for the axonal navigation in $\mathrm{r} 4$ in addition to electroporation studies in chick (Giudicelli et al., 2001) is also supported by the finding in $K$ rox $20^{-1-}$ transgenic mice that trigeminal motor axons are misrouted toward the facial exit point in $\mathrm{r} 4$ (SchneiderMaunoury et al., 1997). We propose that a similar mechanism may link Krox20 expression in r3 to the development of competent reticular neurons from which the episodic generator derives. It is also possible that yet unidentified AP gradients of molecules may produce polarization of $\mathrm{r} 4$ during neurogenesis and neuronal migration, such that competent progenitors are specified only at the anterior border of r4. However, there is as yet no firm evidence either for or against the existence of internal segment polarity within rhombomeres. Additional studies using electrophysiology and selective markers will be necessary to investigate growth of axons and dendrites in the population of parafacial rhythmic neurons developing in $\mathrm{r} 4$.

\section{Development of the parafacial rhythm generator may be conserved in mice and chicks}

The present study provides indications at molecular and regional levels that support the homology of chick and mouse parafacial generators. Although episodic breathing is a rather uncommon or pathological pattern in mammals, it is conserved at a specific embryonic stage in the mouse and in the mature control of pulmonary ventilation in amphibians and has been considered a "physiological phylotypic stage" of hindbrain development in tetrapods (Abadie et al., 2000). The parafacial rhythm in chicks exerts a prominent control over more posterior generators (Fortin et al., 1999). The chick parafacial generator could therefore retain caudal outputs comparable with those of the murine parafacial respiratory group (Onimaru and Homma, 2003) interacting with the pre-Bötzinger generator (Mellen et al., 2003) and spinal motor neurons (Jankzewski et al., 2002). In keeping with the vital respiratory role of $\mathrm{r} 4$ (Dominguez del Toro et al., 2001) and Krox20 (Chatonnet et al., 2002) in mice, we now demonstrate that a segmental program initiated in $\mathrm{r} 3$ under the control of Krox20 instructs formation of a parafacial rhythmic network in $\mathrm{r} 4$.

\section{Regularity of the rhythm is a chick-specific, Krox20- independent phenotype that depends on the anteroposterior orientation of $\mathrm{r} 4$}

Because AP reversal of $\mathrm{r} 4$ impairs the regularity of the rhythm, AP polarity cues within $\mathrm{r} 4$ are required after $\mathrm{HH} 10$ for the proper development of LF activities. Because regularity of the rhythm was observed in all preparations comprising odd and even rhombomere pairs, whether or not the odd contacts the anterior border of r4, Krox20 is dispensable for regularity of the LF rhythm. Mechanisms whereby r6, unlike other isolated even rhombomeres, generates an irregular LF rhythm are presently not known. The high regularity of embryonic rhythms is a chickspecific character, contrasting with the irregular LF primordial rhythm of mice (Abadie et al., 2000). It seems that several other chick-specific, Krox20-dispensable processes start in $\mathrm{r} 4$ at the beginning of neuronal migration around HH12. Hox genes interact in $\mathrm{r} 4$ with neural specification programs to establish unique cell identities within each rhombomere (Davenne et al., 1999; Gaufo et al., 2000; Dasen et al., 2003; Pattyn et al., 2003). Rhombomere 4-specific phenotypic choices are made at this developmental stage, including the generation of branchiomotor versus serotonergic neurons (Pattyn et al., 2003) and the caudal migration of facial branchiomotor neurons through r5 and r6 (lacking in chicks) (Lumsden and Keynes, 1989; Pata et al., 1999; Garel et al., 2000; Gaufo et al., 2000; Studer, 2001). All of these processes are Krox20 dispensable, although they depend on cell autonomous expression of Hoxb1 and Phox2b (Pattyn et al., 2000), persisting after HH20 (Gaufo et al., 2000; Pattyn et al., 2003). The regularity of parafacial rhythmogenic properties thus suggest that AP reversal alters the organization of the generator as a result of the abnormal AP polarity in $\mathrm{r} 4$ during periods of neurogenesis and neuronal migration outlasting the downregulation of Krox 20 expression in $\mathrm{r} 3$.

Segmentation is a robust developmental strategy resulting from the regionalized expression of a limited number of genes (Von Dassow et al., 2000). Local changes in anteroposterior Hox patterns (Brunet and Ghysen, 1999; Dominguez del Toro et al., 2001) as well as in the interaction of Hox genes with dorsoventral establishment of neuronal diversity (Simon et al., 1995; Gaufo et al., 2003; Pattyn et al., 2003) may offer novel opportunities for the evolution of distinct subsets of neurons and the emergence of novel functions. We have now identified a robust developmental specification mechanism that is instructive for the maturation of the activity pattern of hindbrain neuronal circuits. We also provided insight into the possible adaptive role of odd rhombomeres. Operating upstream of Hox genes during the formation of r3, Krox20 initiates development of a specific parafacial circuit in the hindbrain reticular formation. By providing a link between regionalization of the neural tube and emergence of motor pat- 
terns, Krox20 stands among the candidate molecules through which the genome may interact with behavior during evolution.

\section{References}

Abadie V, Champagnat J, Fortin G (2000) Branchiomotor activities in mouse embryo. NeuroReport 17:141-145.

Barrow JR, Capecchi MR (1996) Targeted disruption of the Hoxb-2 locus in mice interferes with expression of Hoxb-1 and Hoxb-4. Development 122:3817-3828.

Borday C, Abadie V, Chatonnet F, Thoby-Brisson M, Champagnat J, Fortin G (2003) Developmental molecular switches regulating breathing patterns in CNS. Respir Physiol Neurobiol 135:121-132.

Brunet JF, Ghysen A (1999) Deconstructing cell determination: proneuronal genes and neuronal identity. BioEssays 21:313-318.

Chatonnet F, Thoby-Brisson M, Abadie V, Dominguez del Toro E, Champagnat J, Fortin G (2002) Early development of respiratory rhythm generation in mouse and chick. Respir Physiol Neurobiol 131:5-13.

Dasen JS, Liu JP, Jessell TM (2003) Motor neuron columnar fate imposed by sequential phases of Hox-c activity. Nature 425:926-933.

Davenne M, Maconochie MK, Neun R, Pattyn A, Chambon P, Krumlauf R, Rijli FM (1999) Hoxa2 and Hoxb2 control dorsoventral patterns of neuronal development in the rostral hindbrain. Neuron 22:677-691.

Dominguez del Toro E, Borday V, Davenne M, Neun R, Rijli FM, Champagnat J (2001) Generation of a novel functional neuronal circuit in Hoxal mutant mice. J Neurosci 21:5637-5642.

Dupé V, Lumsden A (2001) Hindbrain patterning involves graded responses to retinoic acid signalling. Development 128:2199-2208.

Fortin G, Kato F, Lumsden A, Champagnat J (1995) Rhythm generation in the segmented hindbrain of chick embryos. J Physiol (Lond) 486:735-744.

Fortin G, Jungbluth S, Lumsden A, Champagnat J (1999) Segmental specification of GABAergic inhibition during development of hindbrain neural networks. Nat Neurosci 2:873-877.

Garel S, Garcia-Dominguez M, Charnay P (2000) Control of the migratory pathway of facial branchiomotor neurones. Development 127:5297-5307.

Gaufo GO, Flodby P, Capecchi MR (2000) Hoxb1 controls effectors of sonic hedgehog and Mash1 signaling pathways. Development 127:5343-5354.

Gaufo GO, Thomas KR, Capecchi MR (2003) Hox3 genes coordinate mechanisms of genetic suppression and activation in the generation of branchial and somatic motoneurons. Development 130:5191-5201.

Gavalas A, Davenne M, Lumsden A, Chambon P, Rijli FM (1997) Role of Hoxa-2 in axon pathfinding and rostral hindbrain patterning. Development 124:3693-3702.

Giudicelli F, Taillebourg E, Charnay P, Gilardi-Hebenstreit P (2001) Krox-20 patterns the hindbrain through both cell-autonomous and non cell-autonomous mechanisms. Genes Dev 15:567-580.

Goddard JM, Rossel M, Manley NR, Capecchi MR (1996) Mice with targeted disruption of Hoxb-1 fail to form the motor nucleus of the VIIth nerve. Development 122:3217-3228.

Grapin-Botton A, Bonnin MA, Sieweke M, Le Douarin NM (1998) Defined concentrations of a posteriorizing signal are critical for MafB/Kreisler segmental expression in the hindbrain. Development 125:1173-1181.

Guthrie S, Lumsden A (1992) Motor neuron pathfinding following rhombomere reversals in the chick embryo hindbrain. Development 114:663-673.

Hamburger V, Hamilton H (1951) A series of normal stages in the development of the chick embryo. J Morphol 88:49-92.

Helmbacher F, Pujades C, Desmarquet C, Frain M, Rijli FM, Chambon P, Charnay P (1998) Hoxal and Krox-20 synergize to control the development of rhombomere 3. Development 23:4739-4748.

Irving C, Nieto MA, DasGupta R, Charnay P, Wilkinson DG (1996) Progressive spatial restriction of Sek-1 and Krox-20 gene expression during hindbrain segmentation. Dev Biol 173:26-38.

Jacquin TD, Borday V, Schneider-Maunoury S, Topilko P, Ghilini G, Kato F, Charnay P, Champagnat J (1996) Reorganization of pontine rhythmogenic neuronal networks in Krox-20 knockout mice. Neuron 17:747-758.

Jankzewski WA, Onimaru H, Homma I, Feldman JL (2002) Opioidresistant respiratory pathway from the preinspiratory neurones to ab- dominal muscles: in vivo and in vitro study in the newborn rat. J Physiol (Lond) 545:1017-1026.

Kullander K, Butt SJ, Lebret JM, Lundfald L, Restrepo CE, Rydstrom A, Klein R, Kiehn O (2003) Role of EphA4 and EphrinB3 in local neuronal circuits that control walking. Science 299:1889-1892.

Lumsden A, Keynes R (1989) Segmental patterns of neuronal development in the chick hindbrain. Nature 337:424-428.

Lumsden A, Krumlauf R (1996) Patterning the vertebrate neuraxis. Science 274:1109-1115.

Marshall H, Nonchev S, Sham MH, Muchamore I, Lumsden A, Krumlauf R (1992) Retinoic acid alters hindbrain Hox code and induces transformation of rhombomeres 2/3 into a 4/5 identity. Nature 360:737-741.

Mechta-Grigoriou F, Garel S, Charnay P (2000) Nab proteins mediate a negative feedback loop controlling Krox-20 activity in the developing hindbrain. Development 127:119-128.

Mellen NM, Janczewski WA, Bocchiaro CM, Feldman JL (2003) Opioidinduced quantal slowing reveals dual networks for respiratory rhythm generation. Neuron 37:821-826.

Nieto MA, Bradley LC, Wilkinson DG (1991) Conserved segmental expression of Krox-20 in the vertebrate hindbrain and its relationship to lineage restriction. Development 2:59-62.

Onimaru H, Homma I (2003) A novel functional group for respiratory rhythm generation in the ventral medulla. J Neurosci 23:1478-1486.

Pata I, Studer M, Van Doorninck JH, Briscoe J, Kuuse S, Engel JD, Grosveld F, Karis A (1999) The transcription factor GATA3 is a downstream effector of Hoxb1 specification in rhombomere 4. Development 126:5523-5531.

Pattyn A, Hirsch M, Goridis C, Brunet JF (2000) Control of hindbrain motor neuron differentiation by the homeobox gene Phox $2 \mathrm{~b}$. Development 127:1349-1358.

Pattyn A, Vallstedt A, Dias JM, Samad OA, Krumlauf R, Rijli FM, Brunet JF, Ericson J (2003) Coordinated temporal and spatial control of motor neuron and serotonergic neuron generation from a common pool of CNS progenitors. Genes Dev 17:729-737.

Schneider-Maunoury S, Topilko P, Seitandou T, Levi G, Cohen-Tannoudji M, Pournin S, Babinet C, Charnay P (1993) Disruption of Krox-20 results in alteration of rhombomeres 3 and 5 in the developing hindbrain. Cell 75:1199-1214.

Schneider-Maunoury S, Seitanidou T, Charnay P, Lumsden A (1997) Segmental and neuronal architecture of the hindbrain of Krox-20 mouse mutants. Development 124:1215-1226.

Simon H, Hornbruch A, Lumsden A (1995) Independent assignment of antero-posterior and dorso-ventral positional values in the developing chick hindbrain. Curr Biol 5:205-214.

Studer M (2001) Initiation of facial motoneurone migration is dependent on rhombomeres 5 and 6. Development 128:3707-3716.

Studer M, Lumsden A, Ariza-McNaughton L, Bradley A, Krumlauf R (1996) Altered segmental identity and abnormal migration of motor neurons in mice lacking Hoxb-1. Nature 384:630-634.

Takasu MA, Dalva MB, Zigmond RE, Greenberg ME (2002) Modulation of NMDA receptor-dependent calcium influx and gene expression through EphB receptors. Science 295:491-495.

Theil T, Frain M, Gilardi-Hebenstreit P, Flenniken A, Charnay P, Wilkinson DG (1998) Segmental expression of the EphA4 (Sek-1) receptor tyrosine kinase in the hindbrain is under direct transcriptional control of Krox-20. Development 125:443-452.

Von Dassow G, Meir E, Munro EM, Odell GM (2000) The segment polarity network is a robust developmental module. Nature 406:188-192.

Wilkinson DG (1992) Whole-mount in situ hybridization of vertebrate embryos. In: In situ hybridization. A practical approach (Wilkinson DG, ed), pp 1-83. Oxford: IRL.

Wilkinson DG, Bhatt S, Chavrier P, Bravo R, Charnay P (1989) Segmentspecific expression of a zinc finger gene in the developing nervous system of the mouse. Nature 337:461-464.

Wizenmann A, Lumsden A (1997) Segregation of rhombomeres by differential chemoaffinity. Mol Cell Neurosci 9:448-459.

Xu Q, Mellitzer G, Robinson V, Wilkinson D (1999) In vivo cell sorting in complementary segmental domains mediated by the Eph receptors and ephrins. Nature 399:267-271. 